\title{
Harmonic Coupling Analysis and Suppression Strategy of Grid-connected Photovoltaic Inverter
}

\author{
Tao TONG ${ }^{1}$, Xinyan ZHAN ${ }^{1,2}$,Liang GAO ${ }^{1}$,Jiajun ZHANG $^{1}$ \\ ${ }^{1}$ College of Electric engineering, Xinjiang University, China \\ ${ }^{2}$ Engineering Research Center of Education Ministry for Renewable Energy Power Generation and Grid Technology, \\ Xinjiang University, China
}

\begin{abstract}
For the complex harmonic coupling problem caused by the parallel connection of gridconnected photovoltaic inverters to the grid, the mathematical models of a single three-phase inverter and two three-phase inverters connected in parallel are established in this paper. The transfer function is derived and the resonant characteristics of grid-connected single inverter and parallel grid-connected multi-inverters are analyzed by using Bode diagram. On the basis of the maximum power tracking link, This paper proposes a control strategy which combines the double closed-loop of current by using grid-connected voltage and capacitive current with the proportional feedforward compensation of grid voltage, which maximizes the use of solar energy and has a better harmonic resonance suppression capability at the same time. The effectiveness and correctness of the proposed control strategy are verified by Matlab/Simulink system simulation.
\end{abstract}

\section{INTRODUCTION}

Inverter is the core device of photovoltaic power station. It plays an important role in the utilization of solar energy, but it will produce a series of harmonic resonance problems, which will seriously affect the stability of the system ${ }^{[1]}$. At present, scholars at home and abroad have discussed the design and construction of photovoltaic power plants. It is pointed out that the LCL filter, which is widely used in grid-connected inverter resonance, has a resonant spike between inverter and inverter in [2]. The interaction between inverter and power grid will also cause resonance. In [3], the resonant coupling characteristics of multi-grid-connected inverter are analyzed, and it is pointed out that the resonant peak value and frequency are related to the number of parallel inverters. But the resonance problem of single-phase inverter is only analyzed, the resonant coupling problem of three-phase inverter is not analyzed. The filtering performance and realization method of passive damping and active damping are analyzed in [4] and [5]. Author proposed control strategies to reduce harmonic resonance in the power system, but the experimental results are not very satisfactory in [6] and [7] .

In this paper, the equivalent mathematical model and the expression of transfer function are established, taking grid-connected single inverter and parallel gridconnected two inverters as examples. The coupled resonance characteristics of the inverter are analyzed according to the Bode diagram drawn, and the current outer loop is constructed by using the grid-connected voltage and current through the quasi-PR controller. The control strategy composed of double closed loop of current and proportional feedforward compensation of power network voltage with capacitive current feedback is used to suppress the resonant spike. Finally, the system simulation is built by Matlab/Simulink.

\section{ANALYSIS OF RESONANT CHARACTERISTICS OF SINGLE INVERTER}

According to the power characteristics of grid-connected inverter, the inverter incorporated into the grid can be equivalent to a three-phase $\mathrm{AC}$ voltage source, assuming that the internal resistance of the inverter is the same. Fig.1 is grid-connected equivalent circuit for a single inverter. In figure 1 , the ratio $\mathrm{R}$ is the inverter side inductances, $\mathrm{L}_{11}, \mathrm{~L}_{12}, \mathrm{~L}_{13}$ are the inverter side inductance of the LCL filter; $\mathrm{L}_{21}, \mathrm{~L}_{22}, \mathrm{~L}_{23}$ are grid side inductances of the LCL filter; $\mathrm{C}_{1}, \mathrm{C}_{2}$ and $\mathrm{C}_{3}$ are constitute the capacitors of $\mathrm{LCL}$ filter; $\mathrm{L}_{\mathrm{ga}}, \mathrm{L}_{\mathrm{gb}}, \mathrm{L}_{\mathrm{gc}}$ are grid side inductances for grid side inductance isolation transformer leakage inductance value; $\mathrm{U}_{\mathrm{a}}, \mathrm{U}_{\mathrm{b}}, \mathrm{U}_{\mathrm{c}}$ are sinusoidal voltage sources.

\footnotetext{
*Corresponding author: 1378104278@qq.com,xjcxzxy@126.com,1793346200@qq.com,1624236670@qq.com
} 


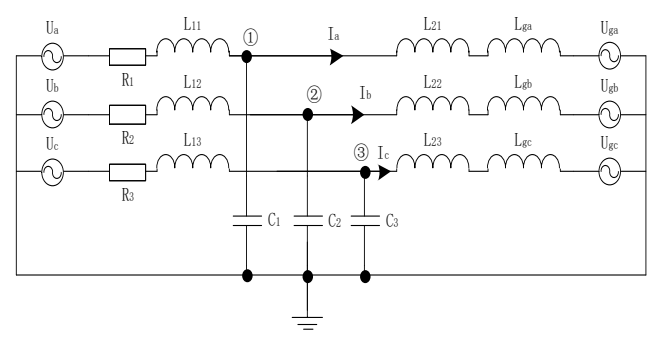

Fig. 1 Single-inverter grid-connected equivalent circuit

$\mathrm{U}_{\mathrm{a}}, \mathrm{U}_{\mathrm{b}}, \mathrm{U}_{\mathrm{c}}$ are equal amplitude, same frequency, initial dependent sub-delay of $120^{\circ}$ sinusoidal voltage sources, other parameters are the same, in order to facilitate the analysis and description, Therefore, the equivalent circuit of three-phase inverter using LCL filter can be simplified to single-phase inverter. In this paper, the equivalent circuit of A phase is drawn, as shown in figure 2. The output current of a single inverter when connected to the grid is equation (1). When the grid voltage is excluded, the output voltage transfer function of the single inverter is equation (2). When only the grid voltage acts alone, the output voltage transfer function of the single inverter is equation (3).

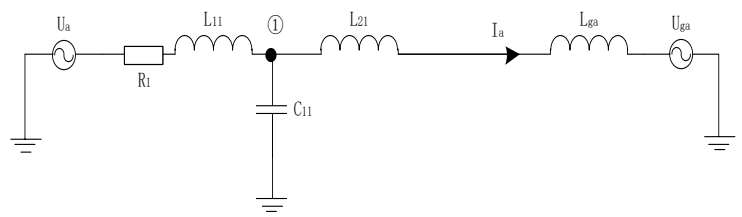

Fig. 2 Grid-connected equivalent circuit of single inverter

$$
\begin{gathered}
I_{a}=\frac{U_{\mathrm{n} 1}-U_{g a}}{s L_{21}+s L_{g a}} \\
G_{1}=\frac{I_{a}}{U_{a}}=\frac{1}{s^{3}\left(C_{11} L_{11} L_{21}+C_{11} L_{11} L_{g a} a\right)+s^{2}\left(C_{11} R_{1} L_{21}+C_{11} R_{1} L_{g a}\right)+s\left(L_{11}+L_{21}+L_{g a}\right)+R_{1}} \\
G_{2}=\frac{I_{a}}{U_{g a}}=\frac{-s^{2} C_{11} L_{11}-s R_{1} C_{11}-1}{s^{3}\left(C_{11} L_{11} L_{21}+C_{11} L_{11} L_{g a} a\right)+s^{2}\left(R_{1} C_{11} L_{21}+R_{1} C_{11} L_{g a}\right)+s\left(L_{11}+L_{21}+L_{g a}\right)+R}
\end{gathered}
$$

The output voltage transfer function of parallel inverter is a complex high-order transfer function, which is related to the impedance values of LCL filter parameters, inverter parameters and grid parameters.

As shown in fig. 3, when a single inverter is connected in parallel to the power network, a high frequency resonant peak occurs at the resonant frequency of the LCL filter at the $1000 \mathrm{~Hz}$ frequency range, and the phase occurs $-180^{\circ}$ jump at the same time. The output current of grid-connected inverter will oscillate. As shown in figure 4, under the action of grid voltage, two high frequency resonant peaks are produced in the $600 \mathrm{~Hz}-1000 \mathrm{~Hz}$ frequency band system, and the phase changes at the same time. The output current of gridconnected inverter also oscillates. Compared with Fig.4, under the condition that only the output voltage is A phase, the system has only one positive resonant peak when the single inverter acts alone, and only when the power grid is acting alone, the system produces a positive resonant spike and a negative resonant spike.

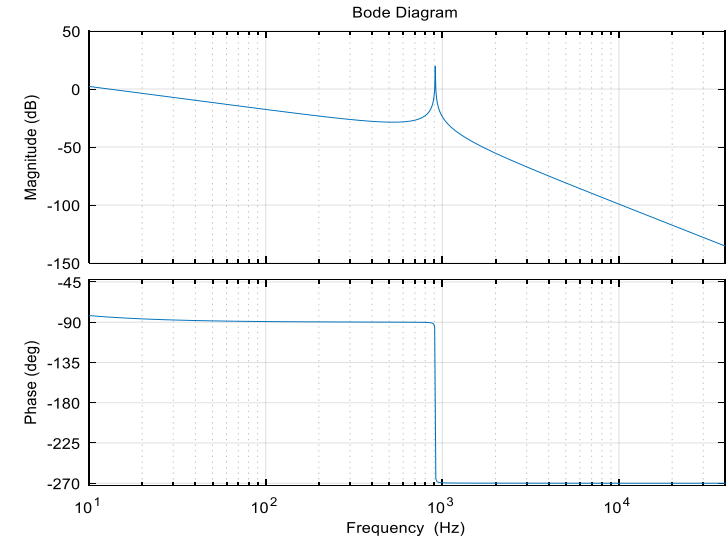

Fig. 3 Bode diagram under the action of single inverter

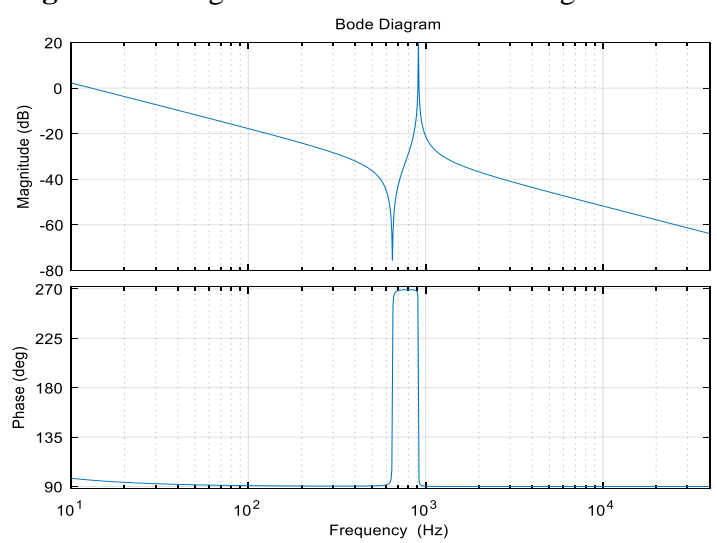

Fig. 4 Bode diagram under the action of grid voltage

\section{CANALYSIS OF PARALLEL RESONANT CHARACTERISTICS OF MULTI-INVERTER}

Taking the A phase of the inverter output voltage as an example, equivalent circuit which is connected in parallel to two the grid inverters with LCL filter is shown in Figure 5.

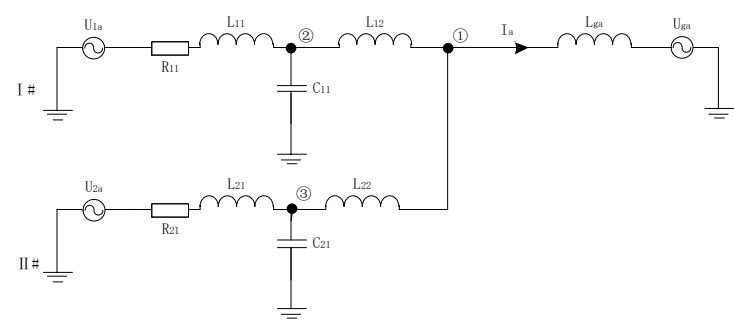

Fig. 5 Grid-connected equivalent circuit of two inverters

In general, all inverters are of the same type in engineering, so the nodal voltage equation (4) is obtained under the condition of three-phase grid voltage balance. When two inverters are connected to the grid, the output current is equation (5). When only I \# inverter acts alone, other voltage sources can be regarded as short circuit, and the output voltage transfer function is equation (6), of which, $\mathrm{Z}_{1}$ is parallel to $\mathrm{R}_{21}, \mathrm{sL}_{21}$ and $\mathrm{sC}_{21}, \mathrm{Z}_{2}$ is parallel to $\mathrm{Z}_{1}, \mathrm{sL}_{22}$ and $\mathrm{sLga}_{\mathrm{ga}}, \mathrm{Z}_{3}$ is parallel to $\mathrm{Z}_{2}, \mathrm{sL}_{12}$ and $\mathrm{sC}_{11}$. When only the grid voltage acts alone, the other voltage sources can be regarded as short circuit, and the output 
voltage transfer function is equation (7), of which, $\mathrm{Z}_{1}$ is parallel to $\mathrm{R}_{11}, \mathrm{sL}_{21}$ and $\mathrm{sC}_{21}, \mathrm{Z}_{2}$ is parallel to $\mathrm{R}_{21}, \mathrm{sL}_{21}$ and $\mathrm{sC}_{21}, \mathrm{Z}_{3}$ is parallel to $\mathrm{Z}_{1}, \mathrm{sL}_{12}$ and $\mathrm{Z}_{2}, \mathrm{sL}_{22}$.

$$
\begin{aligned}
& {\left[\begin{array}{ccc}
\frac{1}{s\left(L_{12}+L_{22}+L_{g a}\right)} & -\frac{1}{s L_{12}} & -\frac{1}{s L_{22}} \\
-\frac{1}{s L_{12}} & \frac{1}{s\left(R_{11}+L_{11}+L_{12}+C_{11}\right)} & 0 \\
-\frac{1}{s L_{22}} & 0 & \frac{1}{s\left(R_{21}+L_{21}+L_{22}+C_{21}\right)}
\end{array}\right]\left[\begin{array}{l}
U_{n 1} \\
U_{\mathrm{n} 2}
\end{array}\right]=\left[\begin{array}{c}
\frac{U_{g a}}{s L_{g a}} \\
\frac{U_{1 a}}{R_{11}+s L_{11}} \\
\frac{U_{2 a}}{R_{21}+s L_{21}}
\end{array}\right]} \\
& I_{a}=\frac{U_{n 2}-U_{n 1}}{s L_{12}}+\frac{U_{n 3}-U_{n 1}}{s L_{22}} \\
& G_{3}=\frac{I_{a}}{U_{1 a}}=\frac{Z_{1}+s L_{22}}{\left(Z_{3}+R R_{11}+s L_{11}\right)\left(s C_{11} Z_{3}+1\right)\left(Z_{1}+s L_{22}+s L_{g a}\right)} \\
& \boldsymbol{G}_{4}=\frac{\boldsymbol{I}_{a}}{\boldsymbol{U}_{g a}}=\frac{\mathbf{1}}{Z_{5}+\boldsymbol{s} \boldsymbol{L}_{g a}}
\end{aligned}
$$

By contrast, we can see that the higher the order of the output voltage transfer function, the more complex the expression is, the more the output current of multiple inverters. The output current of multiple inverters connected to the grid is not only related to the number of parallel inverters, but the characteristics of the power grid also affect the value of the grid.

The Bode diagram of the No.1 inverter acting alone is shown in figure 6 . In the $500 \mathrm{~Hz}-1100 \mathrm{~Hz}$ frequency range, the system produces more high-frequency resonant peaks, there are more high-frequency resonant spikes. Compared with figure 3 , with the increase of the number of parallel inverters, there will be more resonant spikes in the system. The system will be more unstable. Considering only one inverter acting alone, the system will have two positive resonant spikes and one negative resonant spike, and the number of resonant spikes is obviously higher than that of a single inverter connected to the grid. It shows that the increase of the number of grid-connected inverters seriously affects the stability of the system. As shown in Fig. 7, the system also produces more high-frequency resonant spikes in the frequency range of $500 \mathrm{~Hz}$ and $1100 \mathrm{~Hz}$, and the phase increases suddenly in this frequency band. The system will oscillate, as compared with figure 4 , when the grid is acting alone, the number of resonant spikes generated by the system does not vary with the number of inverters. The same conclusion can be obtained when more inverters are connected in parallel to the grid.

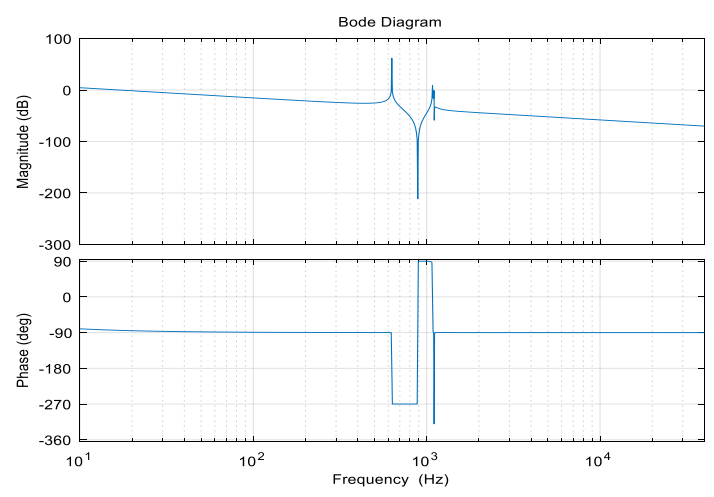

Fig. 6 Bode diagram under single action of $1 \#$ inverter

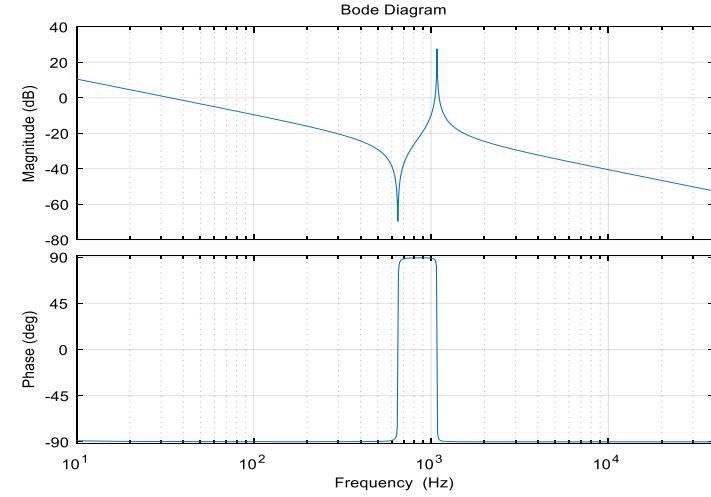

Fig. 7 Bode diagram under the action of power grid

\section{HARMONIC ANALYSIS}

SUPPRESSION

The transfer function of quasi-resonant PR controller is following:

$$
G_{P R}=K_{P}+\frac{2 s \omega_{c} K_{r}}{s^{2}+2 \omega_{c}+\omega_{0}^{2}}
$$

The values of $K_{P}, \omega_{c}$ and $K_{r}$ are determined according to the tuning method of three parameters of transfer function of resonant PR controller in [8].

In order to eliminate the influence of grid-connected voltage on grid-connected current, the feedforward compensation link of grid voltage is added to the control system. Its transfer function is following:

$$
G_{f}=\frac{1}{K_{P W M}}\left(\frac{1}{K_{C}}+\frac{K_{P W M}}{s}\right)
$$

In the formula: $K_{P W M}$ is the ratio coefficient of the PWM generator, and $K_{C}$ is the ratio coefficient of the capacitance current feedback.

The control block diagram is shown in Figure 8, $\mathrm{G}_{\text {inv }}(\mathrm{s})$ is transfer function for inverter equivalent, $\mathrm{G}_{\mathrm{d}}(\mathrm{s})$ is transfer function which considered to be 1.5 times of the inverter digital delay, $\mathrm{K}_{\mathrm{g}}(\mathrm{s})$ for the grid current feedback coefficient, $\mathrm{K}_{\mathrm{C}}$ (s) for the capacitor current feedback coefficient. The electric current by $\mathrm{K}_{\mathrm{g}}(\mathrm{s})$ form the current outer loop feedback capacitance current by $\mathrm{K}_{\mathrm{C}}(\mathrm{s})$ current loop formed dual loop current, grid voltage by $\mathrm{G}_{\mathrm{f}}$ module voltage proportional feedforward and the control strategy by the grid current feedback loop and capacitor current feedback consisting of double loop and electric network voltage feed-forward combination from figure 8 .

The open loop transfer function of the system is following:

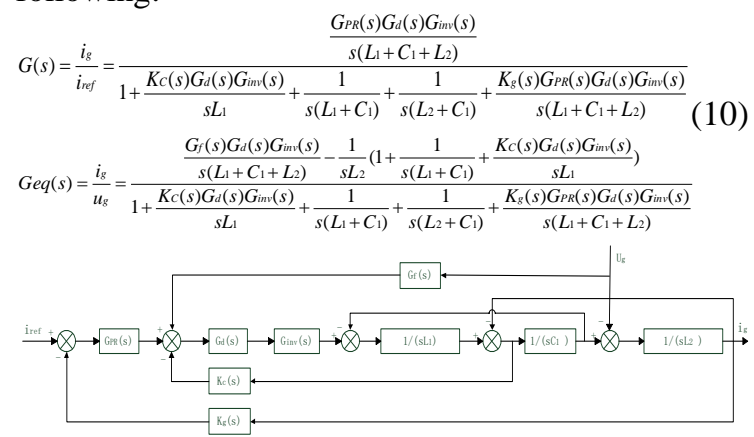

Fig. 8 Inverter control block diagram

The topology and control structure of three-phase photovoltaic inverter system using LCL filter is shown in 
figure 9. The maximum power point instruction voltage is obtained by MPPT module which is composed of realtime measurement of output current and voltage of DC photovoltaic array. After comparing the instruction voltage with the output voltage of the photovoltaic array, the modulation signal of the SPWM control module is obtained by Pi controller. The PLL is used to synchronize the given value of the grid-connected current iref with the grid voltage. The power network current is controlled by quasi-PR controller, the filter capacitive current feedback constitutes the inner loop of the system current double closed loop, and the grid voltage feedback constitutes the system voltage proportional feedforward compensation link.

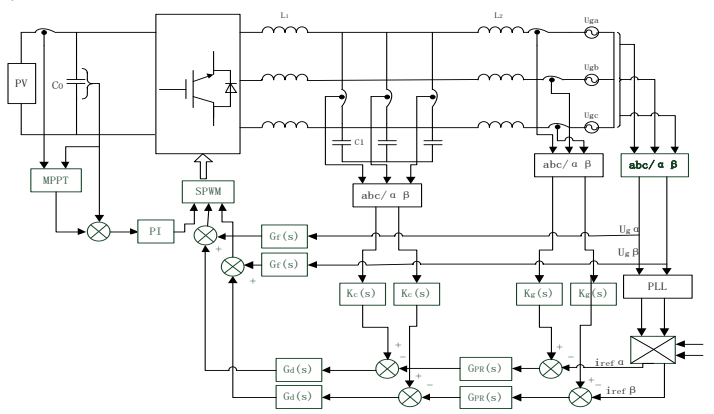

Fig. 9 Photovoltaic inverter system and control structure

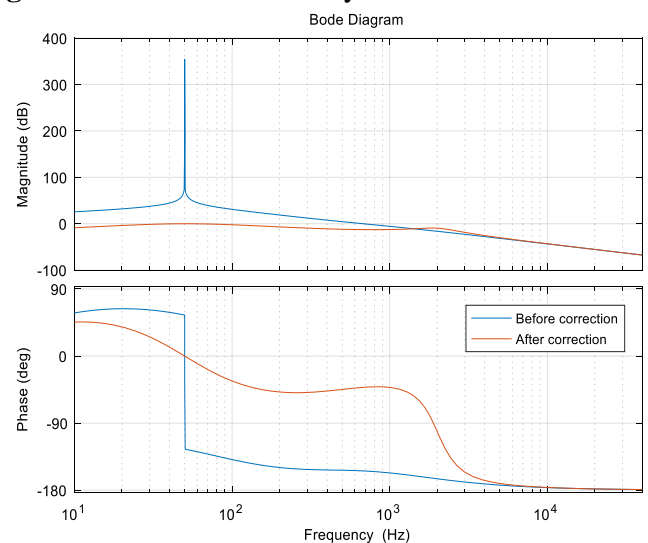

Fig. 10 Bode diagram of output current

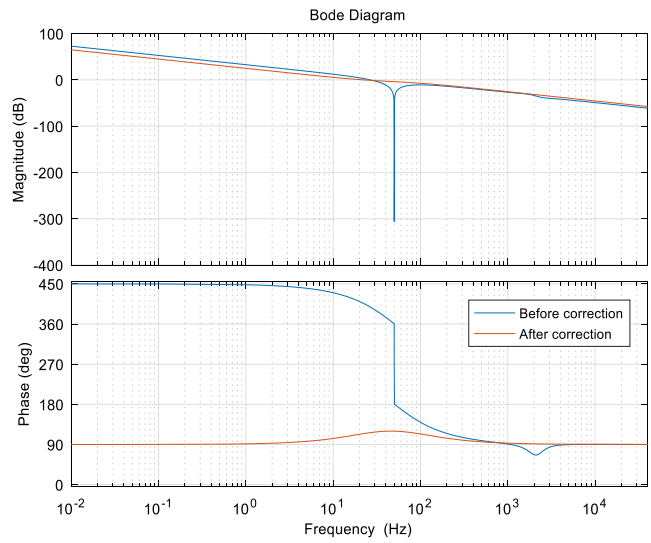

Fig. 11 Bode diagram under the action of power grid

From figure 10, it can be seen that the system has a resonant peak and a phase jump of $-180^{\circ}$ in the frequency range of $50 \mathrm{~Hz}$. The high frequency resonance peak of the system can be effectively suppressed by using the current feedback of the power network and the capacitor current feedback of the filter to form the control strategy of the double closed loop of the system current.
The designed system has good stability. As shown in figure 11, the output currents of the system under the action of the voltage of the power network before and after the controller are shown in figure 11. The system has a negative resonant peak at $50 \mathrm{~Hz}$ frequency and sudden phase change. The feedforward compensation can eliminate the disturbance of the voltage and track the signal without difference. Therefore, the control strategy adopted in this paper can effectively restrain the influence of the grid voltage on the grid-connected current.

In order to verify the correctness of the theoretical analysis, the simulation model is built in Matlab/Simulink, and the harmonic analysis is carried out after three periods after the output A phase voltage is stabilized. From figure 12, we can see that the control strategy adopted in this paper can make the output line voltage quickly stable, the sinusoidal degree is better, the THD of the output voltage is $0.00 \%$, and the high order harmonic suppression is better.

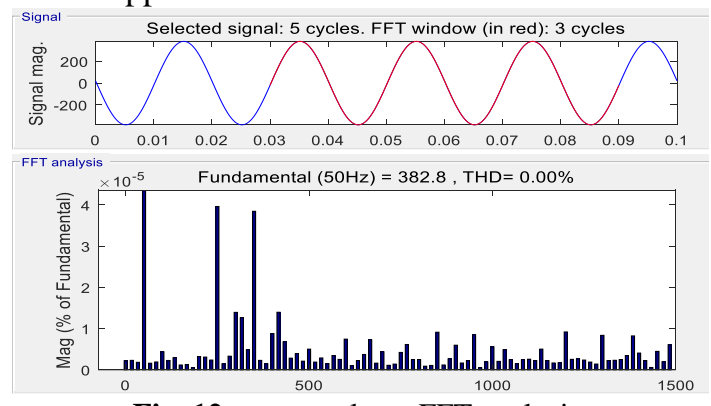

Fig. 12 output voltage FFT analysis

\section{CONCLUSION}

Because the harmonic resonance coupling of LCL threephase photovoltaic inverter, the mathematical models of grid-connected single inverter and two-inverter gridconnected are established, and the expression of transfer functions are derived. The resonance peak of LCL threephase photovoltaic inverter is not only related to the parameters of LCL filter, but also affected by the number of inverter and the voltage of power grid. The more the number of parallel inverters, the more the number of parallel inverters. The system will produce more resonant spikes, and the system will become more unstable. The current outer loop composed of grid voltage and power grid current and the current loop in capacitive current form a double closed loop of current, which is then combined with the proportional feedforward compensation link of power network voltage. This control strategy can counteract the influence of the grid voltage on the grid-connected current and suppress the resonance peak of the system. Finally, the correctness and validity of the strategy are verified by Matlab/Simulink system simulation.

\section{ACKNOWLEDGEMENTS}

This research was financially supported by the National Natural Science Foundation of China (Grant No.51667018\&No.51367015). 


\section{REFERENCES}

1. Liu Guannan. Development status and Prospect of grid connected technology of photovoltaic power generation $[\mathrm{J}]$. research on modern state-owned enterprises, 2017 (22): 135.

2. Liu Huaiyuan, Xu Dianguo, Wu Jian, Gao Qiang, Wang Xiongfei. Analysis, detection and elimination of resonance of grid-connected converter system $[\mathrm{J}]$.Proceedings of the CSEE $(\mathrm{J})$.

3. Zhu Xiaohui, Yuan Yuxia, Zhang Qinghui. Coupled resonant characteristics of Multi-grid Inverter [J] .Journal of Shenyang University of Technology (J).

4. Beres R,Wang X,Blaabjerg F,et al.A review of passive filters for grid-connected voltage source converters[C]// IEEE Applied Power Electronics Conference and Exposition(APEC).Fort Worth:IEEE,2014:2208-2215.

5. Xu Jin-ming, Xie Shao-jun, Xiao Huafeng .LCL filter active damping Control Mechanism [J] .Proceedings of the CSEE (Journal of Electrical Engineering)

6. Zhang Baogong, Zhan long. Harmonic suppression Strategy of Three-phase LCL Grid-connected Inverter [J] .Power Capacitor and reactive Power compensator 2017 / 38 / 05: 165-170.

7. Li Rui, Deng Lei, Li Xiaoqian, et al. Grid-connected Control of LCL Inverter based on Capacitance Voltage Feedforward [J] .Electrical Transmission, 2017,477U: 37-42.

8. Zhou Li, Zheng Danhua.Quasi-PR control of threephase photovoltaic grid-connected inverter using LCL filter [J] .High-voltage electrical apparatus 201753 / 05 / 75-81.

9. Wang Yuncheng, Chen Xin, Zhang, Chen Jie, Gong Chunying. Analysis of frequency characteristics and stability of three phase grid connected inverter phase locked loop [J]. proceedings of the ActA, 2017,37 (13): 3843-3853.

10. Yu Changzhou, Zhang Xing, Liu Fang, Li Fei, Xu Haizhen, Cao Renxian. String type [J]. Journal of solar energy resonance characteristics of three level photovoltaic inverter parallel system common mode, 2017,38 (09): 2394-2402.

11. Wang Baohua.LCL three-phase grid connected inverter adaptive control strategy and its parameters design $[\mathrm{J}]$. power system protection and control, 2017,45 (14): 134-142.

12. He Guofeng, Zhu Genghui, Chu Xiaonan, Han Yaofei, Samaranch Xun, Zhang Xiaojie. [J]. renewable energy analysis of multi inverter grid stability, 2017,35 (03): 389-394. 